\title{
Catalytic performance of heteroatom-modified carbon nanotubes in advanced oxidation processes
}

\author{
João Restivo, Raquel P. Rocha, Adrián M. T. Silva, José J. M. Órfão, Manuel F. R. Pereira, \\ José L. Figueiredo*
}

Laboratory of Catalysis and Materials-Associate Laboratory LSRE/LCM, Faculty of Engineering, University of Porto, Rua Dr. Roberto Frias, $4200-465$ Porto, Portugal

\section{A R T I C L E I N F O}

Article history:

Received 3 April 2014

Accepted 17 April 2014

Published 20 June 2014

\section{Keywords:}

Advanced oxidation processes

Catalytic ozonation

Catalytic wet air oxidation

Sulfur groups

Nitrogen groups

Oxygen groups

Carbon nanotubes

Surface chemistry

\begin{abstract}
A B S T R A C T
Multi-walled carbon nanotubes (CNTs) were submitted to chemical and thermal treatments in order to incorporate different heteroatoms on the surface. $\mathrm{O}-, \mathrm{S}$ - and $\mathrm{N}$-containing groups were successfully introduced onto the CNTs without significant changes of the textural properties. The catalytic activity of these heteroatom-modified CNTs was studied in two liquid phase oxidation processes: catalytic ozonation and catalytic wet air oxidation (CWAO), using oxalic acid and phenol as model compounds. In both cases, the presence of strongly acidic 0-containing groups was found to decrease the catalytic activity of the CNTs. On the other hand, the introduction of S species (mainly sulfonic acids) enhanced the removal rate of the model compounds, particularly in the CWAO of phenol. Additional experiments were performed with a radical scavenger and sodium persulfate, in order to clarify the reaction mechanism. Nitrogen functionalities improve the catalytic performance of the original CNTs, regardless of the process or of the pollutant.
\end{abstract}

(C) 2014, Dalian Institute of Chemical Physics, Chinese Academy of Sciences. Published by Elsevier B.V. All rights reserved.

\section{Introduction}

The presence of organic pollutants that show some resistance to conventional treatment technologies for water and wastewater led to a growing interest in the development of more efficient methods for their removal [1-3], such as the so-called advanced oxidation processes, which include catalytic wet air oxidation (CWAO) and catalytic ozonation processes [4-7].

Several heterogeneous catalysts based on supported or unsupported metal oxides and noble metals have been investi- gated in CWAO [8] and catalytic ozonation [9]. However, deactivation phenomena are frequent, in particular leaching of active metals. In spite of advances in the development of heterogeneous catalysis with minimal leaching effects [10,11], the use of metal-free catalysts has been recently preferred in many advanced oxidation processes, not only to avoid possible lixiviation of metals, but also because these materials are stable in both acidic and alkaline media.

The ability of carbon materials to enhance the removal of organic pollutants by the ozonation process is well-known, and has been demonstrated with activated carbons [12-16], mul-

\footnotetext{
* Corresponding author. Tel: +351-225081663; Fax: +351-225081449; E-mail: jlfig@fe.up.pt This work was supported by FREECATS, the European Union 7th FP (2007-2013) grant no. 280658, PEst-C/EQB/LA0020/2013, FEDER through COMPETE-Programa Operacional Factores de Competitividade, by FCT-Fundação para a Ciência e a Tecnologia, NORTE-07-0124-FEDER-0000015, NORTE-07-0162-FEDER-000050, QREN, ON2, FEDER. 
ti-walled carbon nanotubes (CNTs) [17-21], carbon xerogels [22] and carbon nanofibers [17,23-26]. Similarly, various carbon materials have been used as catalysts for wet air oxidation, including activated carbons [27-29], carbon fibres [30], carbon foams [30], carbon xerogels [27,31] and CNTs [32-36]. The catalytic activity of carbon materials in liquid phase oxidation processes can be enhanced by modification of their textural and chemical properties $[37,38]$. While the effect of the textural properties, such as pore size and surface area, is well understood [21,35,39-41], the role of surface chemistry is still not completely established. In particular, the presence of surface heteroatoms, such as $\mathrm{O}, \mathrm{S}$, and $\mathrm{N}$, has been shown to significantly affect the catalytic activity of carbon materials in catalytic ozonation $[16,21,39,42-48]$ and in the CWAO process $[29,30$, 32-34,49].

In this work, a systematic study was performed to assess the influence of $\mathrm{O}, \mathrm{S}$, and $\mathrm{N}$ heteroatoms on the surface of carbon nanotubes in catalytic wet air oxidation and catalytic ozonation. For this goal, CNTs were prepared with different surface chemical properties, which were applied in the oxidation of two model compounds: oxalic acid and phenol. The performance of the catalysts was then related to their chemical properties, and the oxidation mechanisms for the CNTs with different surface groups were discussed.

\section{Experimental}

\subsection{Materials}

Commercial multi-walled carbon nanotubes (CNT-0), purchased from NANOCYL ${ }^{\mathrm{TM}}$ (NC3100), were subjected to different chemical and thermal treatments in order to modify the original surface properties. Four samples were obtained: CNT-N, prepared by liquid-phase oxidation of the pristine CNTs with nitric acid at boiling temperature; CNT-NUT, obtained by treating CNT-N with urea at $200{ }^{\circ} \mathrm{C}$ to incorporate nitrogen-containing surface groups, followed by gas-phase thermal treatment under nitrogen at $600{ }^{\circ} \mathrm{C}$; CNT-S, obtained by sulfuric acid treatment of the pristine CNTs at $50{ }^{\circ} \mathrm{C}$ in order to introduce strong acidic functional groups (sulfonic groups); and CNT-NS, by refluxing the pristine $\mathrm{CNTs}$ with a $\mathrm{HNO}_{3} / \mathrm{H}_{2} \mathrm{SO}_{4}$ mixture $(1: 3$ $\mathrm{v} / \mathrm{v}$ ) at $50{ }^{\circ} \mathrm{C}$. More detailed information about the experimental conditions can be found elsewhere [32,34].

\subsection{Characterization}

Textural properties of the pristine and modified CNT samples were based on the $\mathrm{N}_{2}$ adsorption isotherms determined at $-196^{\circ} \mathrm{C}$ using a Quantachrome Nova 4200e apparatus. Surface chemistry of the samples was characterized by combining different techniques: temperature programmed desorption (TPD) in a fully automated AMI-300 Catalyst Characterization apparatus (Altamira Instruments) connected to a Dycor Dymaxion Mass Spectrometer monitoring $\mathrm{CO}, \mathrm{CO}_{2}$ and $\mathrm{SO}_{2}$ released during the thermal analysis; X-ray photoelectron spectroscopy (XPS) performed in a Kratos AXIS Ultra HSA using a monochromatic $\mathrm{Al} K_{\alpha} \mathrm{X}$-ray source $(1486.7 \mathrm{eV})$; determination of the
$\mathrm{pH}$ at the point of zero charge $\left(\mathrm{pH}_{\mathrm{pzc}}\right)$ using a drift method [21]. Further description of the techniques can be found elsewhere $[32,34]$.

\subsection{Experimental procedure}

Ozonation experiments were performed in a stirred semibatch tank reactor at room temperature and pressure. A volume of $700 \mathrm{~mL}$ of solution was used, consisting of a $90 \mathrm{mg} / \mathrm{L}$ solution of oxalic acid or $75 \mathrm{mg} / \mathrm{L}$ of phenol. Ozone, generated from pure oxygen using a BMT 802X ozone generator, was bubbled into the bulk of the solution using a diffusor (total flow rate $=150 \mathrm{~cm}^{3} / \mathrm{min}$; ozone concentration $=50 \mathrm{~g} / \mathrm{m}^{3}$ ). Ozone in the gas phase was monitored using a BMT 964 ozone analyser. $100 \mathrm{mg}$ of the powdered catalysts with a particle size between 0.1 and $0.3 \mathrm{~mm}$ were introduced into the solution before starting gas flow admission and kept in suspension by stirring at $200 \mathrm{rpm}$. Blank (no catalyst) and adsorption (no ozone) tests were also performed. In the adsorption experiment, pure oxygen was kept flowing to maintain the mixing conditions of the ozonation tests.

CWAO experiments with phenol and oxalic acid were performed in a $160 \mathrm{~mL} 316-\mathrm{SS}$ high pressure batch reactor housing a glass liner (Parr Instruments, USA Mod. 4564). $200 \mathrm{mg}$ of catalyst were added to $75 \mathrm{~mL}$ of the organic pollutant solution and placed into the reactor. The reactor was flushed with pure nitrogen till complete removal of oxygen, pressurized with 5 bar of $\mathrm{N}_{2}$ and then pre-heated up to the desired temperature under continuous stirring at $500 \mathrm{rpm}$ in order to ensure proper mass transfer of oxygen in the liquid phase [27,31]. When the desired temperature was reached, pure air was injected to obtain a total pressure of 40 bar inside the reactor (corresponding to 7 bar of $\mathrm{O}_{2}$ partial pressure), this being considered time zero for the reaction. The temperatures and the initial concentrations of oxalic acid and phenol were selected after preliminary experiments and by taking into account the concentration of oxygen that is dissolved in the liquid phase at the selected temperatures and pressures [32]. Therefore, CWAO of oxalic acid was performed at $140{ }^{\circ} \mathrm{C}(1000 \mathrm{mg} / \mathrm{L}$ of oxalic acid as starting solution) and phenol experiments at $160{ }^{\circ} \mathrm{C}(75 \mathrm{mg} / \mathrm{L}$ of phenol as starting solution). In addition, non-catalytic wet air oxidation (WAO) and adsorption experiments (absence of oxygen, 40 bar of $\mathrm{N}_{2}$ ) were performed.

CWAO and ozonation experiments were carried out at the natural $\mathrm{pH}$ of the solutions, no buffer being added. The carbon materials were recovered at the end of each run for further characterization.

In order to obtain additional mechanistic information, experiments were also performed in the presence of a radical scavenger, tert-butanol $(t-\mathrm{BuOH})$, with a concentration ten times higher than the organic compound. Additionally, experiments using sodium persulfate $\left(\mathrm{Na}_{2} \mathrm{~S}_{2} \mathrm{O}_{8}\right)$ in the absence and presence of carbon material were performed under the same operating conditions, to provide further insight into the role of the S-containing groups. The amount of sodium persulfate used in the ozonation and CWAO experiments was fixed taking into account the amount of catalyst used in each process and the $\mathrm{S}$ 
content of sample CNT-S, as determined by TPD.

\subsection{Analytical techniques}

Samples periodically withdrawn from the reactors were analysed by high performance liquid chromatography (HPLC) with a Hitachi Elite LaChrom system equipped with a UV-Vis detector (L-2450). A Bio-Rad Aminex HPX-87H column (300 $\mathrm{mm} \times 7.8 \mathrm{~mm}$ ) and a sulfuric acid solution ( $4 \mathrm{mmol} / \mathrm{L})$ at a flow rate of $0.6 \mathrm{~mL} / \mathrm{min}$ (as mobile phase) were used for the determination of oxalic acid concentration. The quantification of oxalic acid was performed at $\lambda=210 \mathrm{~nm}$, with a maximum relative standard deviation of $\pm 2 \%$. In phenol oxidation experiments, the samples were analysed in a Purospher Star RP-18 endcapped column (250 $\mathrm{mm} \times 4.6 \mathrm{~mm}, 5 \mu \mathrm{m}$ particles) working at room temperature. The mobile phase was a mixture of water and methanol 40/60 (v/v) with a flow rate of $1 \mathrm{~mL} / \mathrm{min}$. The total organic carbon (TOC) was also determined using a Shimadzu TOC-5000A analyser.

\section{Results and discussion}

\subsection{Characterization of CNT samples}

Chemical and textural properties of the original and treated CNT samples are described in Table 1. Regarding the textural properties determined from the $\mathrm{N}_{2}$ adsorption isotherms, Table 1 shows that differences between BET surface areas $\left(S_{\mathrm{BET}}\right)$ of pristine and modified CNT samples are smaller than $100 \mathrm{~m}^{2} / \mathrm{g}$. These differences may result from the opening of the CNTs endcaps by treatment with nitric acid [50]. However, the chemical surface properties of the CNT samples were strongly affected by the applied treatments, originating materials with different functional groups, distinguishable by their decomposition temperature [38], and, by consequence, with different chemical properties.

As expected, a very large increase of the oxygen content was observed after nitric acid oxidation (negligible amount in the CNT-O sample) due to the formation of oxygen-containing functional groups on the CNT surface (sample CNT-N). This is

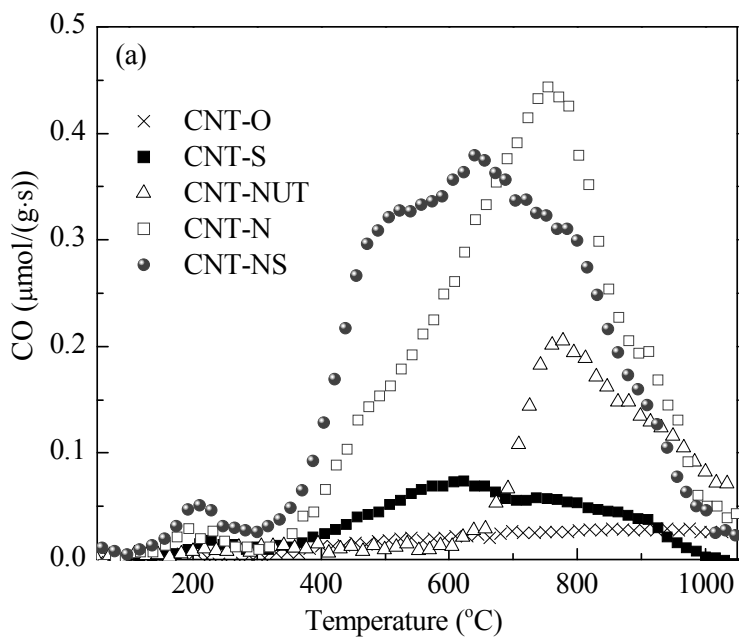

Table 1

Chemical and textural properties of the original and modified carbon nanotube samples.

\begin{tabular}{lccccc}
\hline Sample & $\begin{array}{c}S_{\text {BET }} \\
\left(\mathrm{m}^{2} / \mathrm{g}\right)\end{array}$ & $\begin{array}{c}\mathrm{CO} \\
(\mu \mathrm{mol} / \mathrm{g})\end{array}$ & $\begin{array}{c}\mathrm{CO}_{2} \\
(\mu \mathrm{mol} / \mathrm{g})\end{array}$ & $\begin{array}{c}\mathrm{SO}_{2} \\
(\mu \mathrm{mol} / \mathrm{g})\end{array}$ & $\mathrm{pH}_{\mathrm{pzc}}$ \\
\hline CNT-O & 326 & 187 & 33 & - & 6.8 \\
CNT-N & 400 & 1852 & 1233 & - & 2.2 \\
CNT-NUT & 386 & 701 & 72 & - & 7.3 \\
CNT-S & 294 & 381 & 195 & 579 & 2.5 \\
CNT-NS & 394 & 2035 & 1394 & 203 & 4.8 \\
\hline
\end{tabular}

shown by the large increase in the amounts of $\mathrm{CO}$ and $\mathrm{CO}_{2}$ released by TPD. In particular, the $\mathrm{CO}_{2}$ profile (Fig. 1(b)) shows that the CNT-N sample presents a large amount of carboxylic acid and carboxylic anhydride groups. Regarding the $\mathrm{CO}$ profile (Fig. 1(a)), it is also possible to observe a remarkable formation of phenol and carbonyl/quinone groups. In the CNT-NUT sample, the surface only contains phenol and carbonyl/quinone groups, and a small amount of lactones. In fact, the groups that evolve below $600{ }^{\circ} \mathrm{C}$ (essentially carboxylic acids and anhydrides) were removed by the final gas-phase thermal treatment applied after the urea treatment. Therefore, the amounts of $\mathrm{CO}$ and $\mathrm{CO}_{2}$ are significant smaller than in sample CNT-N.

A large amount of oxygen containing groups was also successfully incorporated using the $\mathrm{H}_{2} \mathrm{SO}_{4} / \mathrm{HNO}_{3}$ mixture (sample CNT-NS), while the amounts of $\mathrm{CO}$ and $\mathrm{CO}_{2}$ released during TPD in the CNT-S sample reveal an insignificant increase of the oxygen surface groups. For sulfuric acid treated samples (CNT-NS and CNT-S), the release of $\mathrm{SO}_{2}$ during the TPD analyses was observed only in the specific temperature range between 200 and $400{ }^{\circ} \mathrm{C}$ (spectra shown later in Fig. 5), revealing the presence of S-containing groups on the surface of the CNTs, due to the decomposition of sulfonic groups (strong acidic groups) into $\mathrm{SO}_{2}$ species [51-53]. In agreement with the $\mathrm{H}_{2} \mathrm{SO}_{4}$ concentration used in each treatment, the CNT-S sample released $579 \mu \mathrm{mol} / \mathrm{g}$ of $\mathrm{SO}_{2}$, about three times more than sample CNT-NS $(203 \mu \mathrm{mol} / \mathrm{g})$.

The presence of the different surface groups is corroborated by the $\mathrm{pH}_{\mathrm{pzc}}$ of the samples, shown in Table 1. Samples CNT-N, CNT-S and CNT-NS reveal an acidic nature, with $\mathrm{pH}_{\text {pzc }}$ below 5

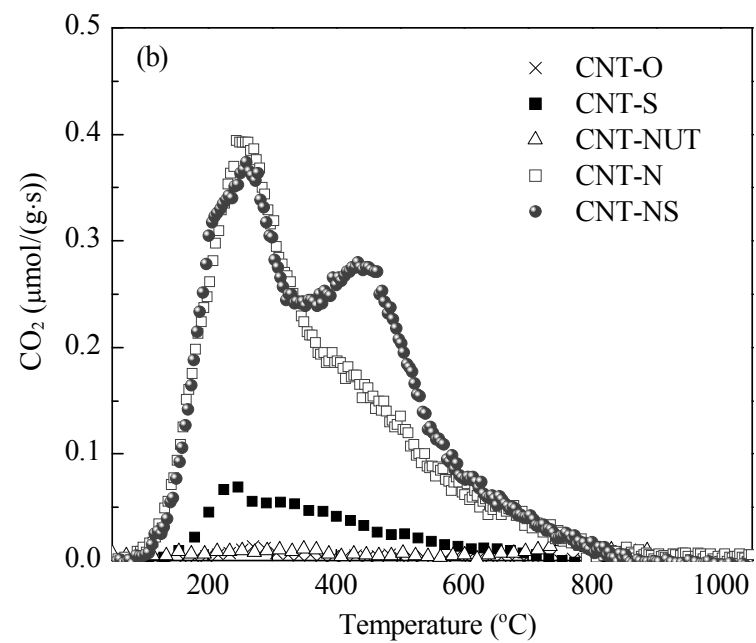

Fig. 1. Profiles of $\mathrm{CO}(\mathrm{a})$ and $\mathrm{CO}_{2}$ (b) evolved in TPD of the original and treated carbon nanotube samples. 
(acidic groups as carboxylic acids, anhydrides, phenols and sulfonic groups are present in the surface of these CNT samples), while neutral or slightly basic $\mathrm{pH}_{\mathrm{pzc}}$ was found for the samples CNT-O and CNT-NUT (negligible amount or absence of acidic groups, and presence of surface neutral and basic groups, such as carbonyl groups, evolved as $\mathrm{CO}$ at temperatures higher than $600{ }^{\circ} \mathrm{C}$ ). Additional surface characterization of CNT-S and CNT-NUT by XPS reveals the presence of sulfonic groups and nitrogen functionalities, respectively. In the case of CNT-S, the sulfonic groups $\left(-\mathrm{SO}_{3} \mathrm{H}\right)$ were identified by the presence of a peak with binding energy of $169 \mathrm{eV}$ in the $\mathrm{S} 2 p$ spectrum [51], corroborating the TPD results. XPS analysis of CNT-NUT showed the presence of pyridine-like N (N6) and pyrrole-like N (N5) atoms on the carbon surface. More detailed characterization can be found elsewhere [32, 34].

\subsection{Oxalic acid and phenol degradation}

The catalytic performance of the pristine and modified CNT samples was studied using oxalic acid (Fig. 2) and phenol (Fig. 3) as model pollutants in ozonation (Figs. 2(a) and 3(a)) and CWAO (Figs. 2(b) and 3(b)). Oxalic acid is poorly oxidized in the absence of a catalyst in both processes (curves labelled $\mathrm{O}_{3}$ in Fig. 2(a), and WAO in Fig. 2(b)). However, an increase in the oxalic acid conversion is observed in both processes in the presence of CNTs. In both cases, oxalic acid is directly mineralized; no by-products are detected by HPLC analysis and the TOC removal corresponds to the oxalic acid disappearance. Furthermore, the adsorption contributions are negligible, as previously reported [21,32].

A clear influence of the surface chemistry of the carbon samples in the catalytic performance can be observed. The acidic samples CNT-N, CNT-NS and CNT-S (which present low $\mathrm{pH}_{\mathrm{pzc}}$ ) underperform compared with the samples with neutral or slightly basic nature (CNT-O and CNT-NUT). In ozonation (Fig. 2(a)), almost complete degradation of oxalic acid can be achieved in 60 min using the pristine CNTs and the N-modified CNT sample, while the oxalic acid conversions are in the range $50 \%-75 \%$ with the S-containing samples (CNT-S and CNT-NS) and CNT-N. Regarding the degradation of oxalic acid by CWAO (Fig. 2(b)), complete oxidation occurs in less than 30 min when samples CNT-O and CNT-NUT are used. Longer reaction times are required to obtain full conversion of oxalic acid with the acidic samples: at least $60 \mathrm{~min}$ with CNT-S, $90 \mathrm{~min}$ with CNT-NS and 120 min with CNT-N.

Due to the large amount of O-containing groups (carboxylic acids and anhydrides, and phenols) on the CNT-N sample, the poor catalytic performance in both processes was expected. In fact, the presence of acidic surface groups in the CNTs has a negative influence in the decomposition of ozone, which is directly related with the efficiency of the catalyst to improve the degradation of refractory organic compounds by ozonation [21,54]. The catalytic activity of CNTs in the degradation of oxalic acid by CWAO was also shown to be negatively affected by the presence of 0-containing surface groups [42]. Furthermore, the positive effect of basicity in liquid-phase oxidations with carbon materials is commonly accepted [37], including the degradation of organic compounds by ozonation [39,41-43, 45-48,54-56] and by CWAO [29,30,34,35].

Nevertheless, sample CNT-NS performs better than CNT-N in CWAO, in spite of its slightly larger amount of surface groups released as $\mathrm{CO}_{2}$ in TPD. This can be ascribed to the presence of S-groups in CNT-NS; indeed, these groups enhance the catalytic activity of the material, as also observed with CNT-S, which is the best of the acidic samples for oxalic acid degradation by CWAO. The presence of sulfonic groups can lead to the formation of active radical species with oxidative potential in the CWAO process. In the case of ozonation, the catalytic activity was clearly improved in the absence of surface acid groups, which suggests that the S-containing surface functionalities do not play a role in this case, as discussed further ahead.

The absence of acidic groups (O-containing or S-containing)

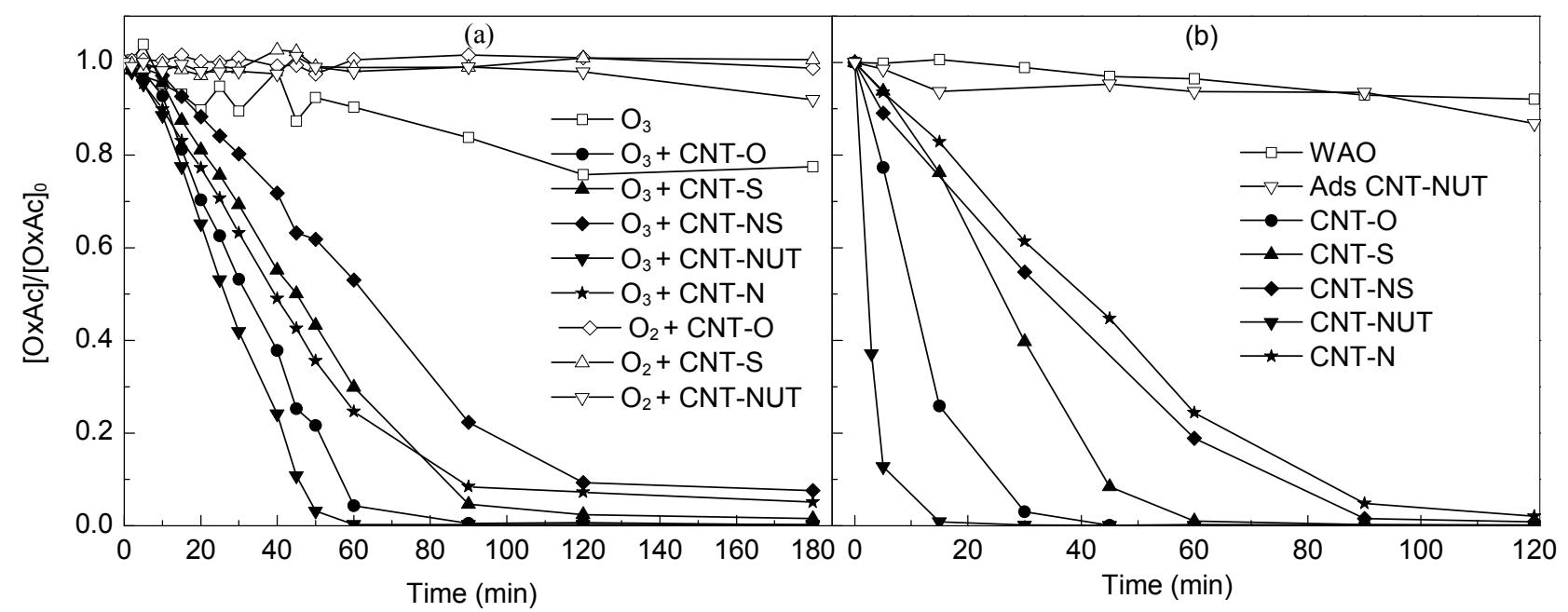

Fig. 2. Dimensionless concentration of oxalic acid during: (a) semi-batch catalytic ozonation and single ozonation $\left(\mathrm{O}_{3}\right)$ experiments (room temperature, $0.1 \mathrm{~g}$ of catalyst; initial concentration of $90 \mathrm{mg} / \mathrm{L}$ ); and (b) CWAO and non-catalytic wet air oxidation (WAO) experiments (140 ${ }^{\circ} \mathrm{C}$, 40 bar of total pressure; $0.2 \mathrm{~g}$ of catalyst; initial concentration of $1000 \mathrm{mg} / \mathrm{L})$. 
leads to a faster degradation of oxalic acid, as observed with samples CNT-O and CNT-NUT, for both processes. The good performance of the pristine CNTs (CNT-O) in catalytic ozonation can be explained by the presence of $\pi$ electrons on the surface, which are known to be active sites for ozone decomposition and formation of radicals [54], but also by the absence of acidic surface species that can hinder the formation of radicals or restrain the surface reaction mechanisms [21,32,47]. The presence of any residual transition metals that might explain the good catalytic activity of sample CNT-O in CWAO can be neglected. In a preliminary work [32], we have observed that HCl-treated CNTs show similar catalytic activity compared with pristine CNTs (the same batch as used in the present study), demonstrating that there are no effects from any residual metals. If such metals were present in the pristine CNTs, they would have been removed by the acid treatment, and a different activity would have been observed.

Concerning the CNT-NUT sample, which shows the best catalytic performance for oxalic acid degradation in both processes, it seems that the $\mathrm{N}$-functionalities introduced are responsible for the improved catalytic activity observed. The results obtained in the catalytic ozonation of oxalic acid support the idea that the increase in electronic density on the surface, promoted by the $\mathrm{N}$-functionalities, favours the reduction of ozone, as recently proposed $[42,45,46,48,56]$. In the CWAO process, the presence of nitrogen groups also seems to favour the interaction of oxygen with the carbon surface [57], with oxygen being possibly activated into species that react with the adsorbed organic pollutant $[42,58,59]$.

Comparison with published results for oxalic acid degradation by catalytic ozonation shows that the CNT-NUT sample performs better than $\mathrm{N}$-doped carbon xerogels [48] and activated carbon [55], which could not allow complete oxalic acid degradation after $120 \mathrm{~min}$, but reveals only a small improvement in performance when compared with other modified commercial CNTs [21], which led to $100 \%$ conversion of oxalic acid in less than $60 \mathrm{~min}$, under similar conditions.

The presence of $\mathrm{N}$-functionalities improves the catalytic ac- tivity of the CNTs in the CWAO process. Sample CNT-NUT shows better performance than several other CNT samples modified by different chemical and thermal treatments [32,34]. When compared with N-doped carbon xerogels (CXs) [48], CNT-NUT leads to total oxalic acid conversion in the same reaction time, but only when using a four times larger amount of catalyst than in the application with CXs (which used only 50 $\mathrm{mg}$ ). In any case, the differences in the nitrogen contents of the different carbon structures $3.8 \%$ in N-CXs and only $0.7 \%$ in CNT-NUT) should not be overlooked.

Figure 3 shows the catalytic activity of the pristine and modified CNT samples in the removal of phenol by ozonation (Fig. 3(a)) and CWAO (Fig. 3(b)). Regarding the ozonation process, phenol reacts promptly with dissolved molecular ozone, and no significant differences are observed in the presence of any of the CNT samples; in addition, adsorption was negligible (Fig. 3(a)). However, slight differences were observed regarding the mineralization, determined by TOC analysis. Complete mineralization of phenol degradation products by ozone requires higher dosages of oxidant and longer contact times when compared with the parent pollutant [60], and may be aided by the addition of a carbon catalyst [61]. In spite of the fast phenol conversion by reaction with ozone, the TOC removals were low, a maximum of $60 \%$-being obtained with the pristine CNTs after $180 \mathrm{~min}$. Analysis of the main aromatic intermediates identified, namely hydroquinone and benzoquinone, did not reveal any significant differences between the catalytic and non-catalytic experiments. Both compounds are formed as soon as the oxidation of phenol begins, and are removed from solution in under $90 \mathrm{~min}$. Organic acids are final by-products of the oxidation of phenol, in particular oxalic acid [60]. The concentrations of oxalic acid accumulated after 180 min (Fig. 3(a), inset) are in complete agreement with what was observed during the ozonation experiments using oxalic acid as a model compound; i.e., the catalysts which showed better performance in the removal of oxalic acid were those that led to a lower concentration of oxalic acid in the experiments with phenol. However, while oxalic acid in the final solution contributed to a

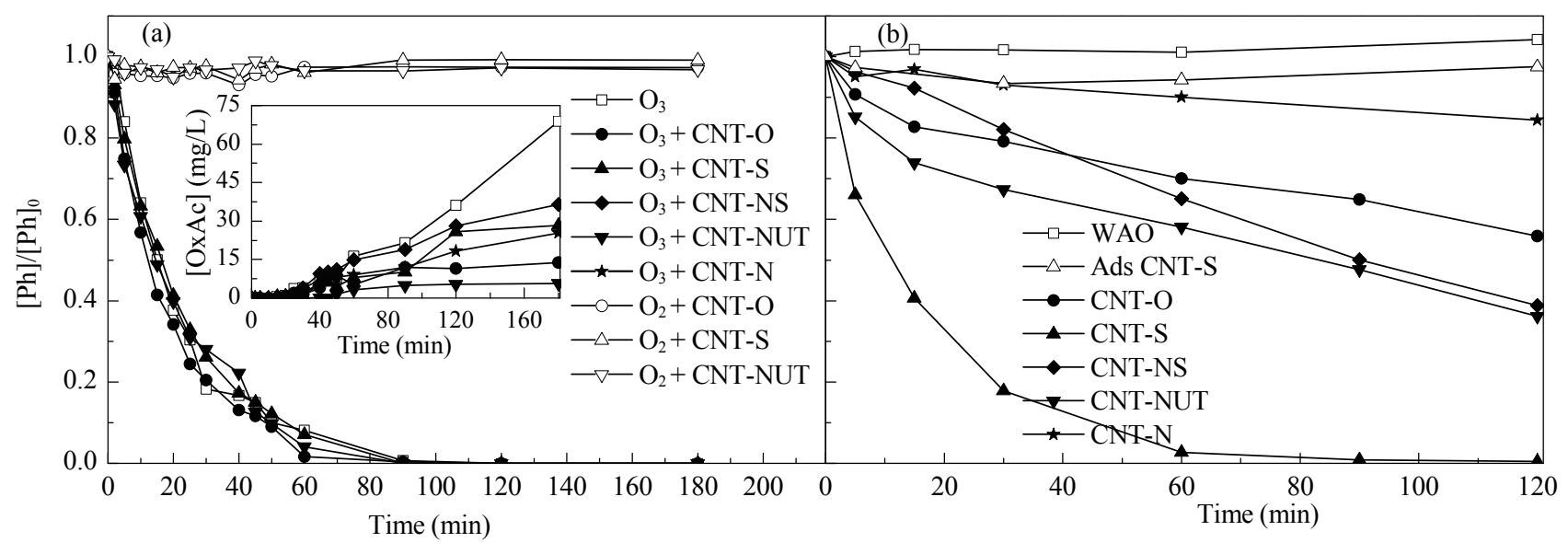

Fig. 3. (a) Dimensionless concentration of phenol during semi-batch catalytic ozonation and single ozonation $\left(\mathrm{O}_{3}\right)$ of phenol (room temperature, $0.1 \mathrm{~g}$ of catalyst; initial concentration of $75 \mathrm{mg} / \mathrm{L}$ ) (inset: oxalic acid concentration during ozonation of phenol); (b) Dimensionless concentration of phenol during CWAO and non-catalytic wet air oxidation (WAO) experiments $\left(160^{\circ} \mathrm{C}, 40\right.$ bar of total pressure; $0.2 \mathrm{~g}$ of catalyst; initial concentration of 75 $\mathrm{mg} / \mathrm{L})$. 
major part of the final TOC (65\% in the case of the single ozonation experiment, $5 \%-25 \%$ in the case of the catalytic ozonation experiments), there was still a large contribution from other organic compounds, which were not identified. The samples containing acidic groups on the surface were the least active catalysts where the mineralization of phenol was concerned, as also observed when oxalic acid was used as a model compound. The improvement in the removal of phenol by addition of activated carbon to the ozonation process has been reported by other authors; however, these results were obtained with a very high loading of catalyst in one case [62], or have been attributed to adsorption in another case [63]. An activated carbon modified by plasma treatment has also been reported to enhance the removal of phenol from water, its activity being ascribed to the increase in the amount of surface oxygenated groups; however, mineralization was not reported in that case [64]. The application of activated carbon as catalyst for the ozonation process to achieve mineralization has resulted in similar observations to what is reported here [61].

Concerning the CWAO process (Fig. 3(b)), phenol was quite stable and resistant in the absence of a catalyst (WAO). Furthermore, adsorption of the model pollutant was negligible regardless of the samples tested. Once again, conversion is faster when the acid character of the carbon samples decreases, suggesting that the absence of strong oxygen-containing acidic groups (such as carboxylic acids and anhydrides) is more favourable for the liquid phase oxidation reactions, CNT-N being the worst catalyst tested (less than $10 \%$ conversion after $2 \mathrm{~h}$ ). Higher phenol removals were achieved with samples CNT-O and CNT-NUT (44\% and 64\%, respectively), the differences highlighting once again the role of the surface nitrogen groups. Nevertheless, the presence of S-containing groups led to a marked increase in the catalytic activity of the CNTs. The samples treated with sulfuric acid showed good performances, particularly sample CNT-S. In spite of the fast phenol conversion achieved with the CNT-S sample, TOC removal was not higher than $57 \%$ after $120 \mathrm{~min}$. Due to the high temperature in the CWAO experiments, sulfonic groups may decompose forming strongly oxidant sulfate radicals, which can be responsible for initiating the degradation of phenol. However, they do not allow high levels of mineralization, suggesting that they can be selective for phenol oxidation but are not able to degrade the various by-products formed (particularly short chain carboxylic acids, as oxalic acid). In fact, the S-modified samples underperformed in the oxalic acid oxidation, in comparison with CNT-O and CNT-NUT. The enhanced activity of activated carbons containing S-groups has already been demonstrated in the catalytic wet peroxide oxidation of acid dyes [52,53]. It was suggested that the presence of the S-species promotes a better adsorption of the probe dye molecule and a faster reaction, in spite of the low reaction temperature $\left(50^{\circ} \mathrm{C}\right)$. Other authors have reported good results in the degradation of phenol by CWAO with CNTs oxidized with mixtures of $\mathrm{H}_{2} \mathrm{SO}_{4}$ and $\mathrm{HNO}_{3}$. However, these results were ascribed to the presence of carboxylic acid groups, neglecting the S-containing groups which can also be incorporated onto the CNTs by such treatment $[33,36,49]$.

\subsection{Characterization of used CNTs}

The catalyst samples (CNT-S and CNT-NUT) recovered after reaction were analysed by TPD and XPS, in order to provide further insights into the reaction mechanisms of ozonation and CWAO. The S $2 p$ spectra obtained by XPS (Fig. 4 ) show that there are no changes in the nature of the sulfur groups of sample CNT-S. Nevertheless, a decrease in the concentration of sulfonic acid groups was observed.

The spectra of $\mathrm{SO}_{2}$ released during TPD experiments with CNT-S samples after ozonation and after CWAO are presented in Fig. 5. It is clear that a large amount of S-containing surface groups is removed from the material during both processes. The loss of sulfur groups was larger after the catalytic experiments, using ozone (COz) or oxygen (CWAO), in comparison to the adsorption or blank (in the absence of organic compound) experiments. TPD analysis of used samples reveals that there is an increase in the concentration of oxygen-containing surface groups after the CWAO and catalytic ozonation experiments. However, this increase is more drastic after ozonation. The nature of these groups is mainly acidic, which may hinder the catalytic performance of these materials $[21,32]$.

The N $1 s$ spectra of the CNT-NUT sample, before and after each oxidation process, are presented in Fig. 6. Samples recovered after CWAO did not show any significant alteration in the $\mathrm{N} 1 s$ spectrum obtained by XPS. Deconvolution of the spectra showed similar relative amounts of N5, N6 and oxidized N (N-X) surface groups. However, a drastic change was observed in the samples used in ozonation. A decrease in the intensity of the peak attributed to N6 (pyridine) was observed. Similar results were reported with carbon xerogels [48]. It has been observed that, in the case of CWAO, $S_{\mathrm{BET}}$ does not considerably change for different CNT samples after several runs [34]. Similar observations were also made for CNT in the case of ozonation [21]. Thus, the surface area of CNT-S is not expected to significantly change during the advanced oxidation processes described.

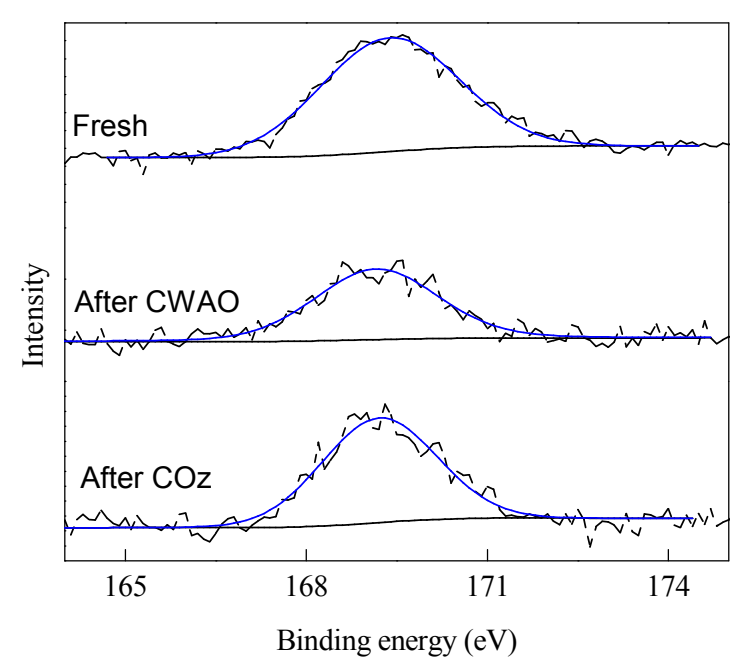

Fig. 4. S $2 p$ XPS spectra of the sulfur-modified carbon nanotube sample (CNT-S) before (fresh) and after catalytic ozonation (COz) and catalytic wet air oxidation (CWAO) experiments with oxalic acid. 


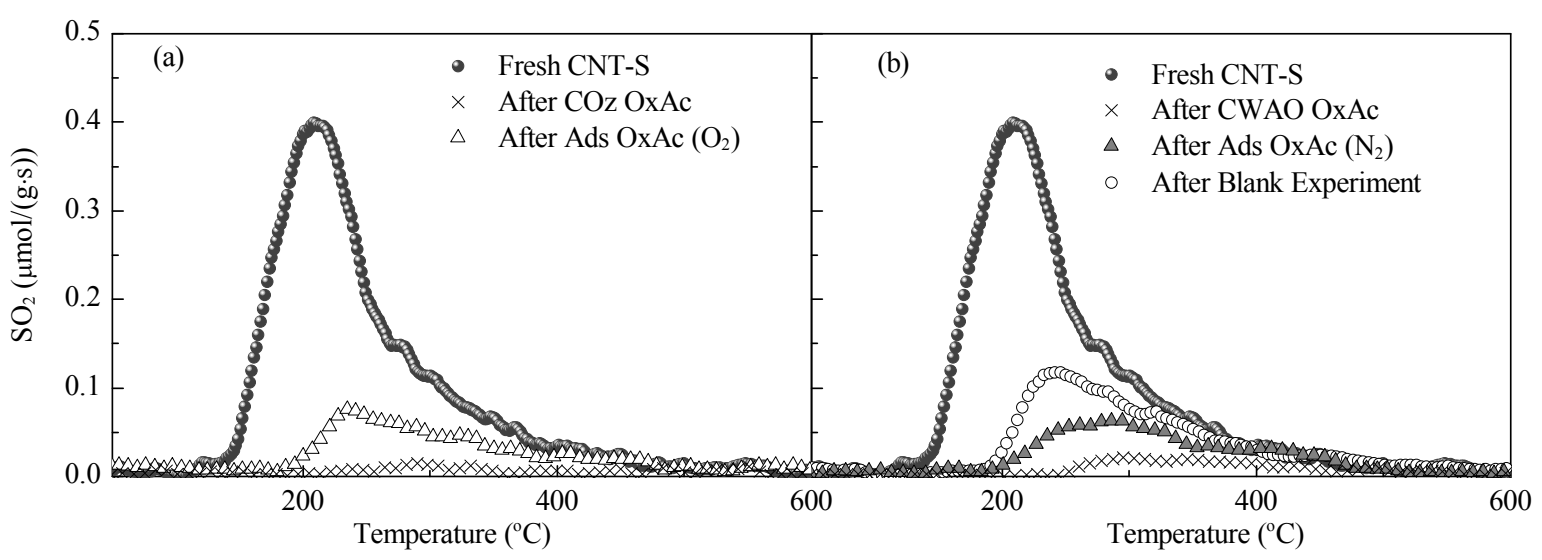

Fig. 5. Spectra of $\mathrm{SO}_{2}$ evolved in TPD of CNT-S before (a) and after (b) oxidation reactions.

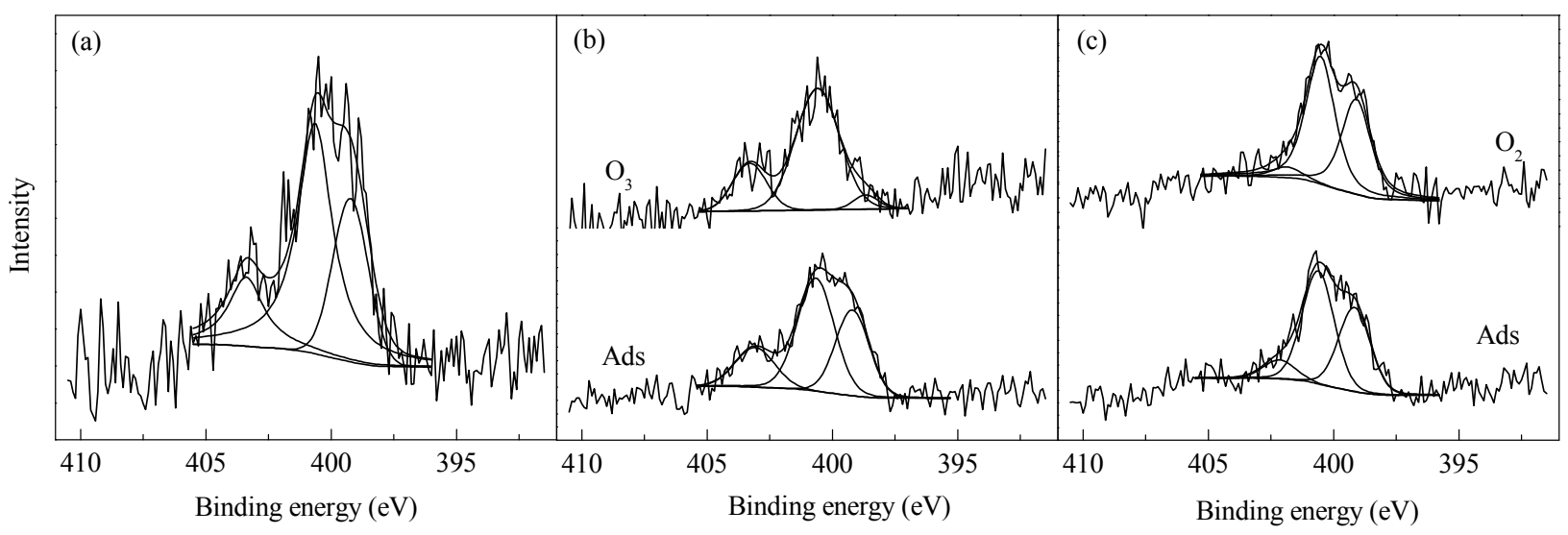

Fig. 6. N 1s XPS spectra of the fresh (a) and used CNT-NUT samples after catalytic ozonation (b), and CWAO (c) experiments.

The stability of samples CNT-0, CNT-N and CNT-NUT has already been evaluated in CWAO [34]. The formation of surface acidic groups slightly hinders their performance, but the catalysts retain good activity in this reaction. The stability of sample CNT-S has also been assessed in CWAO [32]. It was shown that leaching of the S-containing groups hindered the performance of the catalyst in the reactions where these functionalities are more important (i.e. the oxidation of phenol). The recyclability of pristine CNT has already been demonstrated in the case of catalytic ozonation [21]. The introduction of acidic groups on the surface of the samples decreases their catalytic activity. However, after a $2^{\text {nd }}$ run, no further deactivation was observed, since no increase in the amount of acidic groups was detected. A similar behaviour was observed with the CNT samples used in this work. The modification of the $\mathrm{N}$-containing functionalities during ozonation did not result in major changes to the performance of the catalyst after a $2^{\text {nd }}$ reutilization, which was also observed when $\mathrm{N}$-doped carbon xerogels were used in this reaction [48].

\subsection{Mechanistic considerations}

Sodium persulfate and potassium persulfate are strong oxidizing agents often used to form sulfate radicals for several applications where strong oxidant radicals are required. They are frequently used for in-situ chemical oxidation $[65,66]$ and some advanced oxidation technologies [67-72], with the sulfate radical $\left(\mathrm{SO}_{4}{ }^{--}\right)$being produced by thermal activation, reaction with ozone-derived species or photolysis of persulfate anions [73].

In order to better elucidate the reaction pathways involved in ozonation (Fig. 7(a)) and CWAO (Fig. 7(b)) with the S-modified samples, using respectively oxalic acid and phenol as model compounds, sodium persulfate was added as a source of sulfate radicals. The amount of sodium persulfate added to each system was determined by considering the mass of catalyst (100 mg in ozonation and $200 \mathrm{mg}$ in CWAO) and the amount of $\mathrm{SO}_{2}$ released by sample CNT-S in TPD. Therefore, the reactions were performed using equivalent $\mathrm{S}$ molar concentrations. The addition of persulfate ion to the ozonation reaction system enhances the degradation of oxalic acid (Fig. 7(a)). Since the experiment without ozone in the gas feed showed no removal of the pollutant, it is clear that the interaction of ozone, or ozone-derived species, with persulfate, or derived species, is responsible for this positive effect [71,72]. While the reaction of hydroxyl radicals with the persulfate ion is reported to be responsible for the generation of sulfate radicals when AOPs are concerned $[69,71,72]$, the spontaneous homogeneous generation of hydroxyl radicals does not occur at the $\mathrm{pH}$ (3.0) of the initial oxalic acid solution [54]. Thus, it is likely that ozone, or 

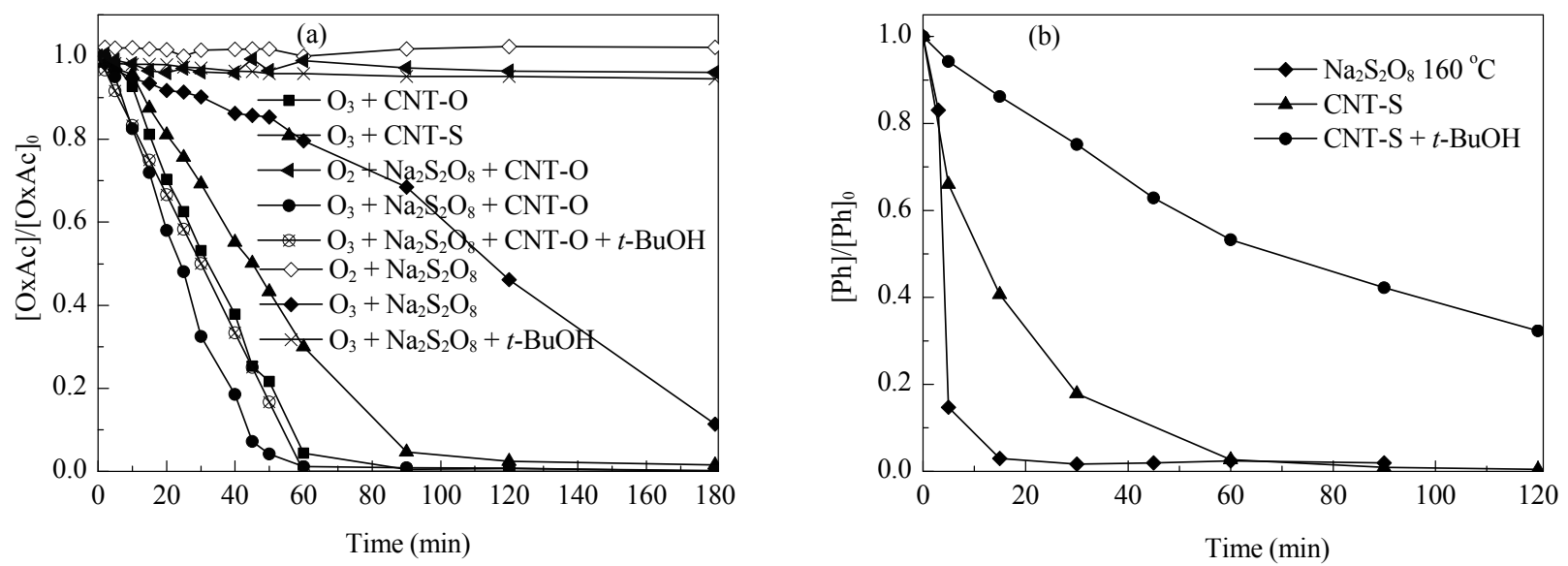

Fig. 7. (a) Oxalic acid degradation under ozonation conditions and (b) phenol removal (under CWAO) performed in the presence or absence of persulfate and with or without the radical scavenger tert-butyl alcohol.

ozone-derived species, activate the persulfate ions, thus forming more active radical species which enhance the degradation of oxalic acid. In fact, no degradation of oxalic acid was observed when tert-butanol $(t-\mathrm{BuOH}$, a known radical scavenger [54]) was added to this reaction system, therefore suggesting the intervention of radical species in the $\mathrm{O}_{3} / \mathrm{Na}_{2} \mathrm{~S}_{2} \mathrm{O}_{8}$ system. A positive effect in the degradation of oxalic acid was observed when $\mathrm{Na}_{2} \mathrm{~S}_{2} \mathrm{O}_{8}$ was added to the $\mathrm{O}_{3}+\mathrm{CNT}-\mathrm{O}$ experiment. This enhanced performance was eliminated in the presence of the radical scavenger, confirming the role of radicals in solution. When the same experiment was carried without ozone in the gas feed $\left(\mathrm{O}_{2}+\mathrm{CNT}-\mathrm{O}+\mathrm{Na}_{2} \mathrm{~S}_{2} \mathrm{O}_{8}\right.$ in Fig. 7(a)), no removal of oxalic acid was observed. It has been suggested that carbon materials can promote the formation of active radicals from persulfate $[68,74]$, but this was not observed in our working conditions (most likely due to the lower concentration of persulfate in solution).

These experiments suggest that the species resulting from the decomposition of S-containing groups during ozonation are not activated by ozone in the same way as persulfate. This seems to be the main difference between CWAO and catalytic ozonation, in regard to the mechanism when the S-containing sample is used. This was confirmed when $t$ - $\mathrm{BuOH}$ was added to the catalytic ozonation of oxalic acid carried out with sample CNT-S (not shown), where no difference in the removal was observed.

In the CWAO process, it was expected that the addition of sodium persulfate could lead to the thermal activation of the sulfate radicals due to the higher operating temperatures. With respect to phenol oxidation, Fig. 7(b) shows that phenol is quickly converted when sodium persulfate is added to the reaction system in the absence of any catalyst ( $\mathrm{Na}_{2} \mathrm{~S}_{2} \mathrm{O}_{8}$ curve). Since phenol is refractory in non-catalytic conditions (WAO), phenol abatement in such experiment should be related to the presence of the sulfate radicals formed by the chemical activation of persulfate ions. Comparing with the CNT-S sample, where a lower rate of phenol conversion was observed, the liquid phase reaction with persulfate leads to a lower mineralization of phenol $37 \%$ of TOC removal after $2 \mathrm{~h}$ of reaction at
$160{ }^{\circ} \mathrm{C}$ with $\mathrm{Na}_{2} \mathrm{~S}_{2} \mathrm{O}_{8}$ vs. $57 \%$ in the CWAO experiment with sample CNT-S). In the additional experiment performed with CNT-S in the presence of $t$-BuOH (Fig. 7(b)), a lower phenol removal rate was observed, and $2 \mathrm{~h}$ of reaction was not enough to attain $100 \%$ conversion. These results lead to the conclusion that, in the case of phenol, the reaction mechanism involves free radicals in solution. In the absence of persulfate ions (with which $t$-BuOH can also react [65]), the radical scavenger can react with hydroxyl radicals. Therefore, the decrease in the phenol degradation rate in the experiment with the CNT-S sample and $t$-BuOH can be due to: (1) hydroxyl radicals in solution that play a role in the phenol oxidation mechanism being quenched by $t$ - $\mathrm{BuOH}$; (2) sulfate radicals formed upon release of the S-groups from the CNT surface being scavenged by $t$ - $\mathrm{BuOH}$; or (3) a synergistic effect of both radicals. In fact, it has been reported that the active species taking part in the oxidation of organic compounds in the carbon/persulfate combined system are both $\mathrm{SO}_{4} \cdot-$ and $\mathrm{OH} \bullet$ radicals $[68,75]$.

\section{Conclusions}

CNTs were successfully functionalized with different heteroatoms, mainly $\mathrm{O}, \mathrm{S}$, and $\mathrm{N}$ containing groups. The effect of these species on the catalytic activity of the CNTs for oxalic acid and phenol degradation by ozonation and by catalytic wet air oxidation was evaluated. Oxalic acid is refractory in the absence of a catalyst, but can be efficiently oxidized using the CNT samples. On the other hand, phenol can be converted by single ozonation, but its mineralization can be improved by the CNT catalysts. In the CWAO process, phenol can only be oxidized in the presence of CNTs. The introduction of acidic oxygen containing groups remarkably leads to a decrease of the catalytic activity of the CNTs. The presence of nitrogen groups leads to a faster removal of the compounds by both processes. The presence of sulfonic groups on the CNTs improves phenol conversion by CWAO, suggesting a possible reaction pathway involving sulfate radicals. In the case of ozonation, no radical action was observed when sample CNT-S was used, in agreement with its performance in the removal of oxalic acid and phenol. 


\section{Acknowledgments}

The authors thank Dr. Carlos Sá at CEMUP for assistance with XPS analyses. J. Restivo and R.P. Rocha acknowledge the PhD grants SFRH/BD/85751/2012 and SFRH/BD/95411/ 2013, respectively. A.M.T. Silva acknowledges the FCT Investigator 2013 Programme (IF/01501/2013), with financing from the European Social Fund and the Human Potential Operational Programme.

\section{References}

[1] Liu Z H, Kanjo Y, Mizutani S. Sci Total Environ, 2009, 407: 731

[2] Bolong N, Ismail A F, Salim M R, Matsuura T. Desalination, 2009, 239: 229

[3] Li D, Qu J.J Environ Sci, 2009, 21: 713

[4] Melo S A S, Trovo A G, Bautitz I R, Nogueira R F P. Quim Nova, 2009, 32: 188

[5] Ikehata K, El-Din M G. Ozone Sci Eng, 2005, 27: 83

[6] Ikehata K, El-Din M G. Ozone Sci Eng, 2005, 27: 173

[7] Levec J, Pintar A. Catal Today, 2007, 124: 172

[8] Kim K-H, Ihm S-K. J Hazard Mater, 2011, 186: 16

[9] Legube B, Leitner N K V. Catal Today, 1999, 53: 61

[10] Gao P, Li C, Wang H, Wang X, Wang A. Chin J Catal (催化学报) 2013, 34: 1811

[11] Xu A, Lu X, Yang M, Du H, Sun C. Chin J Catal (徐爱华, 鲁晓阳, 杨 民, 杜鸿章, 孙承林. 催化学报), 2007, 28: 395

[12] Guzman-Perez C A, Soltan J, Robertson J. Sep Purif Technol, 2011, 79: 8

[13] Pocostales J P, Alvarez P M, Beltrán F J. Chem Eng J, 2010, 164: 70
[14] Beltrán F J, Pocostales J P, Alvarez P M, Jaramillo J. J Hazard Mater, 2009, 169: 532

[15] Beltrán F J, Pocostales P, Alvarez P, Oropesa A.J Hazard Mater, 2009, 163: 768

[16] Faria P C C, Órfão J J M, Pereira M F R. Appl Catal B, 2008, 83: 150

[17] Fan X, Restivo J, Órfão J J M, Pereira M F R, Lapkin A A. Chem Eng J, 2014, 241: 66

[18] Gonçalves A G, Órfão J J M, Pereira M F R. Catal Commun, 2013, 35 : 82

[19] Gonçalves A G, Órfão J J M, Pereira M F R. Appl Catal B, 2013, 140: 82

[20] Gonçalves A G, Órfão J J M, Pereira M F R. J Hazard Mater, 2012, 239: 167

[21] Gonçalves A G, Figueiredo J L, Órfão J J M, Pereira M F R. Carbon, 2010, 48: 4369

[22] Orge C A, Órfão J J M, Pereira M F R. Appl Catal B, 2012, 126: 22

[23] Restivo J, Órfão J J M, Pereira M F R, Garcia-Bordejé E, Roche P, Bourdin D, Houssais B, Coste M, Derrouiche S. Chem Eng J, 2013, 230: 115

[24] Derrouiche S, Bourdin D, Roche P, Houssais B, Machinal C, Coste M, Restivo J, Orfao J J M, Pereira M F R, Marco Y, Garcia-Bordeje E. Water Sci Technol, 2013, 68: 1377

[25] Restivo J, Órfão J J M, Pereira M F R, Vanhaecke E, Rönning M, Iouranova T, Kiwi-Minsker L, Armenise S, Garcia-Bordejé E. Water Sci Technol, 2012, 65: 1854

[26] Restivo J, Órfão J J M, Armenise S, Garcia-Bordejé E, Pereira M F R. J Hazard Mater, 2012, 239-240: 249

[27] Gomes H T, Machado B F, Ribeiro A, Moreira I, Rosário M, Silva A M T, Figueiredo J L, Faria J L. J Hazard Mater, 2008, 159: 420

[28] Gomes H T, Figueiredo J L, Faria J L. Catal Today, 2007, 124: 254

[29] Santiago M, Stüber F, Fortuny A, Fabregat A, Font J. Carbon, 2005,

\section{Graphical Abstract}

Chin. J. Catal., 2014, 35: 896-905 doi: 10.1016/S1872-2067(14)60103-0

\section{Catalytic performance of heteroatom-modified carbon nanotubes in advanced oxidation processes}

João Restivo, Raquel P. Rocha, Adrián M. T. Silva, José J. M. Órfão, Manuel F. R. Pereira, José L. Figueiredo* University of Porto, Portugal

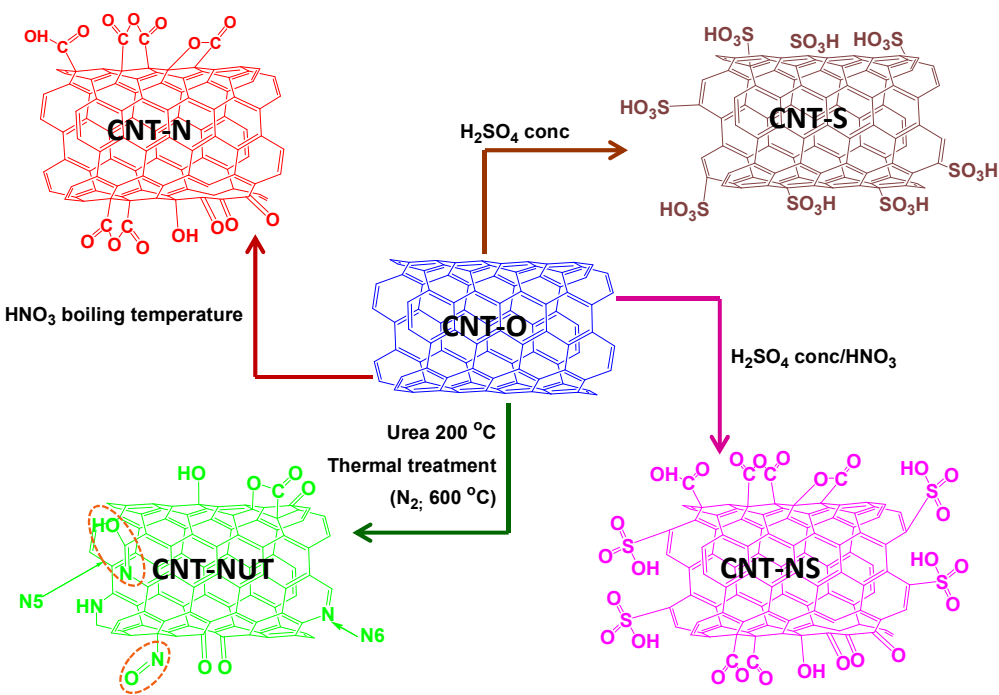

Catalytic ozonation and catalytic wet air oxidation of oxalic acid and phenol using carbon nanotubes functionalized with 0-, S- and $\mathrm{N}$-containing surface groups. 
43: 2134

[30] Sousa J P S, Silva A M T, Pereira M F R, Figueiredo J L. Sep Sci Technol, 2010, 45: 1546

[31] Apolinário Â C, Silva A M T, Machado B F, Gomes H T, Araújo P P, Figueiredo J L, Faria J L. Appl Catal B, 2008, 84: 75

[32] Rocha R P, Silva A M T, Romero S M M, Pereira M F R, Figueiredo J L. Appl Catal B, 2014, 147: 314

[33] Yang S, Wang X, Yang H, Sun Y, Liu Y. J Hazard Mater, 2012, 233-234: 18

[34] Rocha R P, Sousa J P S, Silva A M T, Pereira M F R, Figueiredo J L. Appl Catal B, 2011, 104: 330

[35] Soria-Sánchez M, Maroto-Valiente A, Álvarez-Rodríguez J, MuñozAndrés V, Rodríguez-Ramos I, Guerrero-Ruíz A. Appl Catal B, 2011, 104: 101

[36] Yang S, Zhu W, Li, X, Wang J, Zhou Y. Catal Commun, 2007, 8: 2059

[37] Figueiredo J L, Pereira M F R. Catal Today, 2010, 150: 2

[38] Figueiredo J L, Pereira M F R, Freitas M M A, Órfão J J M. Carbon, 1999, 37: 1379

[39] Liu Z-Q, Ma J, Cui Y-H, Zhao L, Zhang B-P. Sep Purif Technol, 2011, 78: 147

[40] Taran O, Polyanskaya E, Ogorodnikova O, Kuznetsov V, Parmon V, Besson M, Descorme C. Appl Catal A, 2010, 387: 55

[41] Orge C A, Sousa J P S, Gonçalves F, Freire C, Órfão J J M, Pereira M F R. Catal Lett, 2009, 132: 1

[42] Cao H, Xing L, Wu G, Xie Y, Shi S, Zhang Y, Minakata D, Crittenden J C. Appl Catal B, 2014, 146: 169

[43] Liu Z-Q, Ma J, Cui Y-H, Zhao L, Zhang B-P. Appl Catal B, 2010, 101: 74

[44] Sánchez-Polo M, Rivera-Utrilla J. Carbon, 2003, 41: 303

[45] Xing L, Xie Y, Cao H, Minakata D, Zhang Y, Crittenden J C. Chem Eng J, 2014, 245: 71

[46] Liu Z-Q, Ma J, Cui Y-H, Zhang B-P. Appl Catal B, 2009, 92: 301

[47] Beltrán F J, García-Araya J F, Giráldez I. Appl Catal B, 2006, 63: 249

[48] Rocha R P, Restivo J, Sousa J P S, Órfão J J M, Pereira M F R, Figueiredo J L. Catal Today, DOI: 10.1016/j.cattod.2014.04.006

[49] Yang S, Li X, Zhu W, Wang J, Descorme C. Carbon, 2008, 46: 445

[50] Monthioux M, Smith B W, Burteaux B, Claye A, Fischer J E, Luzzi D
E. Carbon, 2001, 39: 1251

[51] Terzyk A P. J Colloid Interface Sci, 2003, 268: 301

[52] Gomes H T, Miranda S M, Sampaio M J, Figueiredo J L, Silva A M T, Faria J L. Appl Catal B, 2011, 106: 390

[53] Gomes H T, Miranda S M, Sampaio M J, Silva A M T, Faria J L. Catal Today, 2010, 151: 153

[54] Faria P C C, Órfão J J M, Pereira M F R. Appl Catal B, 2008, 79: 237

[55] Faria P C C, Órfão J J M, Pereira M F R. Chemosphere, 2007, 67: 809

[56] Sánchez-Polo M, von Gunten U, Rivera-Utrilla J. Water Res, 2005, 39: 3189

[57] Pollak E, Salitra G, Soffer A, Aurbach D. Carbon, 2006, 44: 3302

[58] Chen H, Yang G, Feng Y, Shi C, Xu S, Cao W, Zhang X. Chem Eng J, 2012, 198-199: 45

[59] Szymanski G S, Grzybek T, Papp H. Catal Today, 2004, 90: 51

[60] Turhan K, Uzman S. Desalination, 2008, 229: 257

[61] Beltrán F J, Rivas F J, Montero-de-Espinosa R. J Chem Technol Biotechnol, 2003, 78: 1225

[62] Choi J W, Lee H S. Appl Chem Eng, 2012, 23: 490

[63] Pratarn W, Pornsiri T, Thanit S, Tawatchai C, Wiwut T. Chin J Chem Eng, 2011, 19: 76

[64] Limsuwan P, Kumagai S, Nonaka M, Sasaki K, Tanthapanichakoon W, Hirajima T. Adv Mat Res, 2013, 701: 305

[65] Liang C, Su H-W. Ind Eng Chem Res, 2009, 48: 5558

[66] Yan N, Liu F, Huang W. Chem Eng J, 2013, 219: 149

[67] Olmez-Hanci T, Arslan-Alaton I. Chem Eng J, 2013, 224: 10

[68] Xu X-Y, Zeng G-M, Peng Y-R, Zeng Z. Chem Eng J, 2012, 200-202: 25

[69] Criquet J, Leitner N K V. Chemosphere, 2009, 77: 194

[70] Khan J A, He X, Khan H M, Shah N S, Dionysiou D D. Chem Eng J, 2013, 218: 376

[71] Abu Amr S S, Aziz H A, Adlan M N, Bashir M J K. Chem Eng J, 2013, 221: 492

[72] Abu Amr S S, Aziz H A, Adlan M N. Waste Manage, 2013, 33: 1434

[73] Neta P, Huie R E, Ross A B. J Phys Chem Ref Data, 1988, 17: 1027

[74] Sun H, Kwan C, Suvorova A, Ang H M, Tadé M O, Wang S. Appl Catal B, 2014, 154-155: 134

[75] Yang S, Yang X, Shao X, Niu R, Wang L. J Hazard Mater, 2011, 186: 659 